\title{
ENERGY INTENSITY OF THE ELECTRIC VEHICLE
}

\author{
Mieczysław Dziubiński ${ }^{1}$, Artur Drozd ${ }^{1}$, Marek Adamiec' $^{1}$ Ewa Siemionek ${ }^{1}$ \\ 1 Department of Automotive Vehicles, Lublin University of Technology, Mechanical Engineering Faculty, \\ Nadbystrzycka 36, 20-618 Lublin, Poland, e-mail: m.dziubinski@pollub.pl
}

Received: 2017.09 .26

Accepted: 2017.11.01

Published: 2017.12.05

\begin{abstract}
Continuous energy intensity is a relationship between continuous energy intensity and energy intensity of movement. In the paper we proposed to analyze energy intensity of the movement, as the size specifying the power demand to the wheel drive and presented the balance of power of an electric car moving in the urban cycle. The object of the test was a hybrid vehicle with an internal combustion engine and electric motor. The measurements were carried out for 4 speeds and 2 driving profiles.
\end{abstract}

Keywords: energy intensity, electric vehicle, experimental research

\section{INTRODUCTION}

The basic element of the energy balance of the vehicle is the analysis of the energy intensity of movement. In terms of energy, vehicle movement is the result of longitudinal force, whose task is to balance the resistance movement and to overcome the fictitious force. This force performs work on a given section of road. The counterpart of this work is the expenditure of energy, which should be led to the wheel, which are driven in order to realize the movement of the vehicle. In the vast majority of driving time wheel drive is switched on and the sum of the resistance movement and the fictitious force are balanced by driving force. In other words, energy intensity of movement is the product of the average value of the driving force and the driving distance [2-4, 9-11].

Energy intensity of the movement, as the size specifying the power demand to the wheel drive, depends on the properties of the motor and speed and properties of drive system. Other components of the energy balance of the car losses associated with the processing power in the engine and its transmission to the wheels that depend on specific operating parameters and properties of the drive unit.

Energy intensity of the traffic and drive efficiency are values which determine the energy consumption, whose the value is the basic measure of the energy quality of the construction and operation of the vehicle. Factors affecting the value of the individual components of energy balance are: defined ownership of the vehicle, engine, road and implemented driving profile.

In the case of electric vehicles, energy intensity of traffic constitutes smaller part of the consumed energy than in the case of combustion vehicles $[12,13]$. The vast majority of the losses generated by the combustion propulsion system refers to energy loss. Fig. 1 shows the energy balance of the electric car moving in the urban cycle.

It can be seen that the amount of energy consumed when the vehicle is in motion it is $9.3 \%$ Respectively. This significant difference is due to differences in design and use of different brake systems, transmissions, etc. During operation of the combustion engine, a large part of the energy supplied by the fuel is lost in the form of heat regardless of whether the vehicle is in motion or not. In the case of the electric drive system, power is consumed only when the vehicle is in motion. During the stop, the electric motor is at rest.

Energy consumption of movement consists of several components. It is a total expenditure of energy required to overcome the movement resistance and to overcome the fictitious force, which is present during acceleration. After taking 


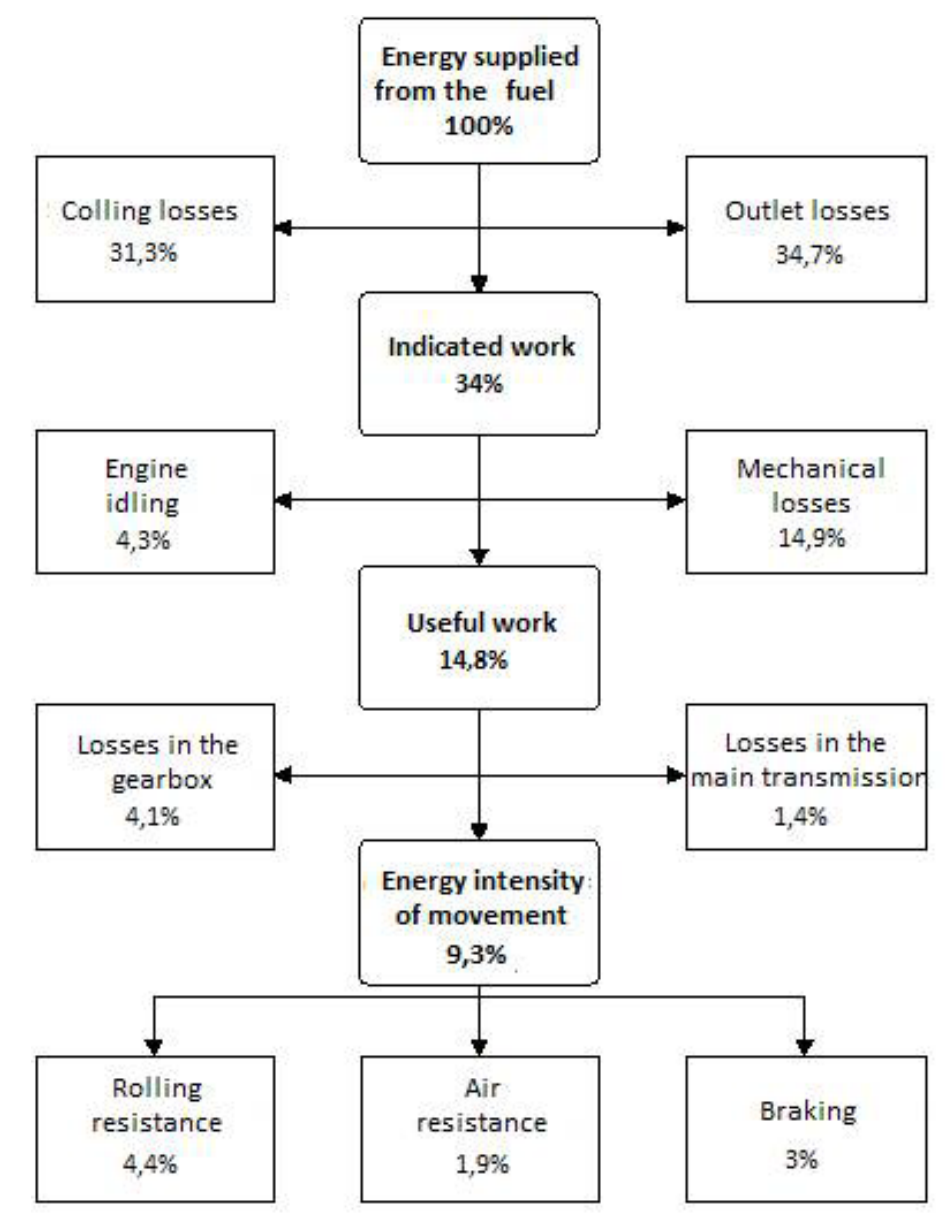

Fig. 1. The balance of power of a car moving in the urban cycle

into account the equivalence of energy and labor, each of the components of the energy intensity of the movement can be expressed in the following product of the force and road:

- the energy needed to overcome the rolling resistance:

$$
E_{t}=m g \int_{0}^{L_{n}} f_{t} \mathbf{d} s
$$

- the energy needed to overcome air resistance:

$$
E_{p}=c_{x} A \varepsilon \int_{0}^{L_{n}} v^{\mathbf{2}} \mathbf{d} s
$$

- the energy needed to overcome the hills

$$
E_{w}=m g \int_{0}^{L^{\prime} n} \sin \alpha \mathbf{d} s
$$

- kinetic energy (or increase)

$$
E_{k}=m \delta \int_{0}^{L_{a}} a(s) \mathrm{d} s
$$

where: $\mathrm{m}$ - vehicle weight $[\mathrm{kg}]$,

$\mathrm{g}$ - acceleration of gravity $\left[\mathrm{m} / \mathrm{s}^{2}\right]$, $\mathrm{c}_{\mathrm{x}}$ - aspect ratio,
A - frontal area of the vehicle $\left[\mathrm{m}^{2}\right]$, $\varepsilon=0.6 \mathrm{~kg} / \mathrm{m}^{3}-0.5$ air density, $\mathrm{f}_{\mathrm{t}}$ - coefficient of rolling resistance, $\delta$ - coefficient of the rotating masses, $\alpha$ - the angle of longitudinal inclination of road $\left[^{\circ}\right]$,

- acceleration $\left[\mathrm{m} / \mathrm{s}^{2}\right]$,

$v$ - speed $[\mathrm{m} / \mathrm{s}]$,

$\mathrm{L}_{\mathrm{n}}$ - distance travelled in the drive phase [m]

$\mathrm{L}_{\mathrm{n}}$ - distance travelled when passing over hills [m].

The speed profile of the vehicle moving at variable speed includes all the basic movement phase, which is listed in the correct order. They are called elementary profiles. These are the acceleration, driving at the same speed and delayed movement. In the case of this type of movement of energy value needed to reach a given road section also determines the frequency and intensity of occurrence of deceleration. Quality indicators 


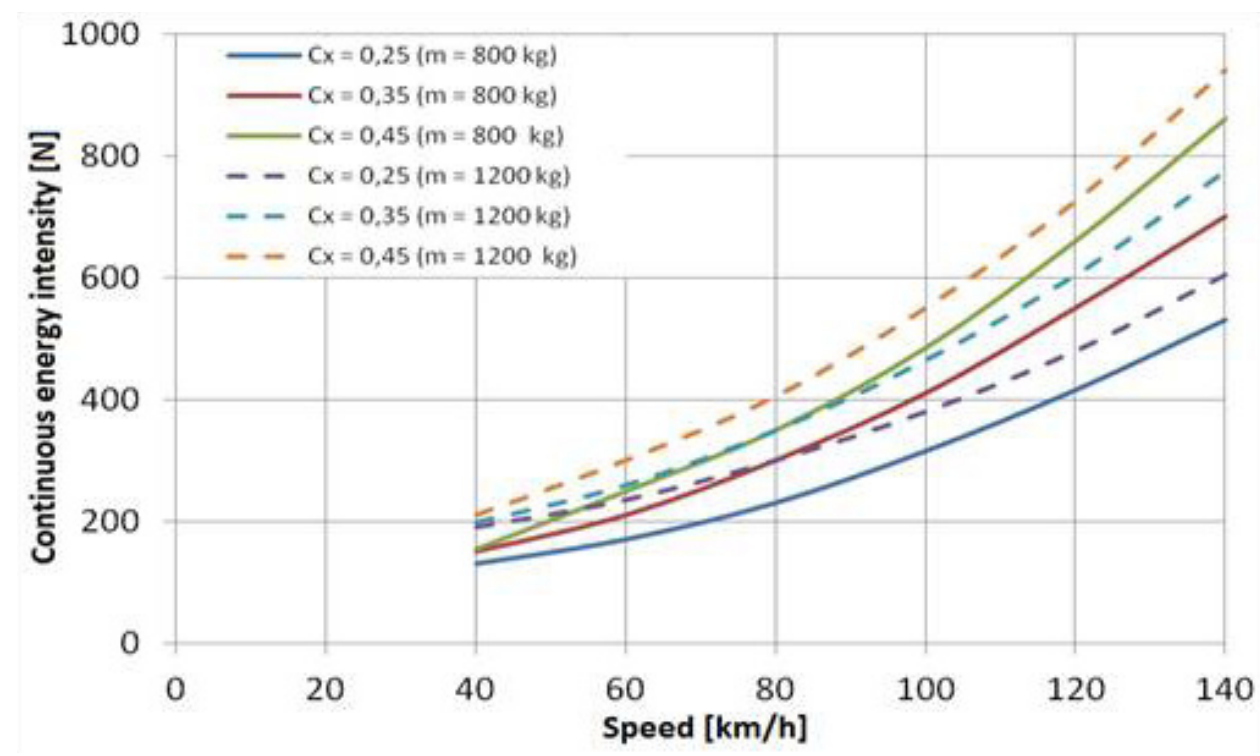

Fig. 2. Continuous energy intensity of the course at a constant speed for different values of the coefficient of the shape and weight of the vehicle

of energy movement were introduced to help determine energy requirements. These include: continuous energy intensity expressed by the ratio of energy output to the road and the energy consumption of the unit, which is the ratio of energy output to the product of the mass and roads.

Continuous energy intensity is a relationship between continuous energy intensity and energy intensity of movement. According to the literature "for a given average value of efficiency of the drive, continuous energy intensity is proportional to the ratio of the energy intensity to the distance travelled [14].

$$
\Psi=\frac{E}{L}
$$

where: $E$ - the sum of the movement resistance

[J]

$L$ - the length of the road, on which motion resistance acts on the vehicle [m]

This volume is a comparative indicator of quality energy of the vehicle, with specific design parameters, which moves according to the assumed speed profile (Fig. 2). Continuous energy intensity has a dimension of strength. This figure expresses driving force on wheels for the movement forced by transfer of power from the engine to the wheels. But for the speed profile including both phases of driving and delayed movement, the unit energy intensity shows the average value of the resultant axial force."
The unit energy intensity $\Phi$ is the ratio of the energy intensity of movement to the product of the vehicle mass and distance expressed in the following units: $\frac{k J}{k g * m}, \frac{k N}{k g}, \frac{m}{s^{2}}$

$$
\Phi=\frac{E}{m L}
$$

In the general principle, the unit energy intensity can be represented by the sum of:

$$
\Phi=g f_{t} \Theta_{t}+k_{m} \varepsilon \Theta_{p}+\Theta_{b}
$$

where:

$$
k_{m}=\frac{c_{x} A}{m}
$$

$k_{m}$ - factor containing the basic design parameters of the vehicle, determining the movement resistance.

$Q_{b}$ - the unit expenditure of energy used to overcome fictitious force during acceleration.

The value of the component $\mathrm{Q}_{\mathrm{b}}$, when accelerating at a certain speed range, depends entirely on the implemented speed profile, which decides about distance travelled.

Because $\mathrm{E}_{\mathrm{k}}=\mathrm{m} * \overline{\mathrm{a}} * \mathrm{~L}_{\mathrm{a}}$, therefore, the ratio of kinetic energy to the product of the mass and road presents the average acceleration for elementary speed profile. "

Energy demand during the movement of the vehicle and irregularities in the construction can be determined by analyzing the individual parameters. 


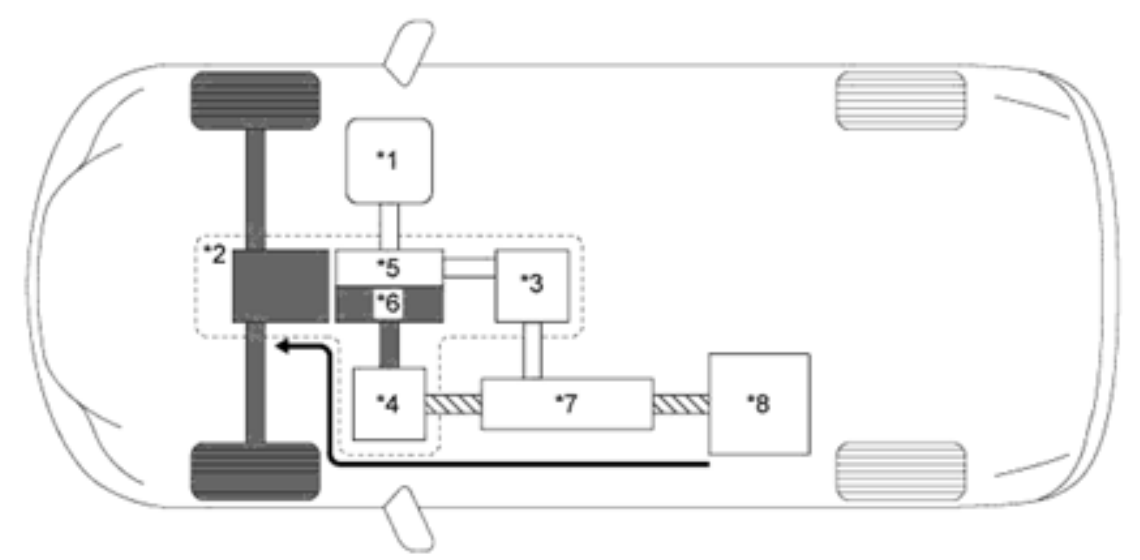

Fig. 3. Block diagram of the hybrid drive system

$* 1$ - motor (off) $* 2$-transmission in a hybrid drive system; $* 3$ - engine - generator MG1; * 4-engine - generator MG2;*5-planetary gear, which separates power; $* 6$ - planetary gear reducing the speed of the electric motor; $* 7$ - inverter unit with converter; $* 8$ - battery; $\square$ - power transmitted mechanically, $\mathbb{M}$ - power transmitted electrically; - the direction of transfer of power.

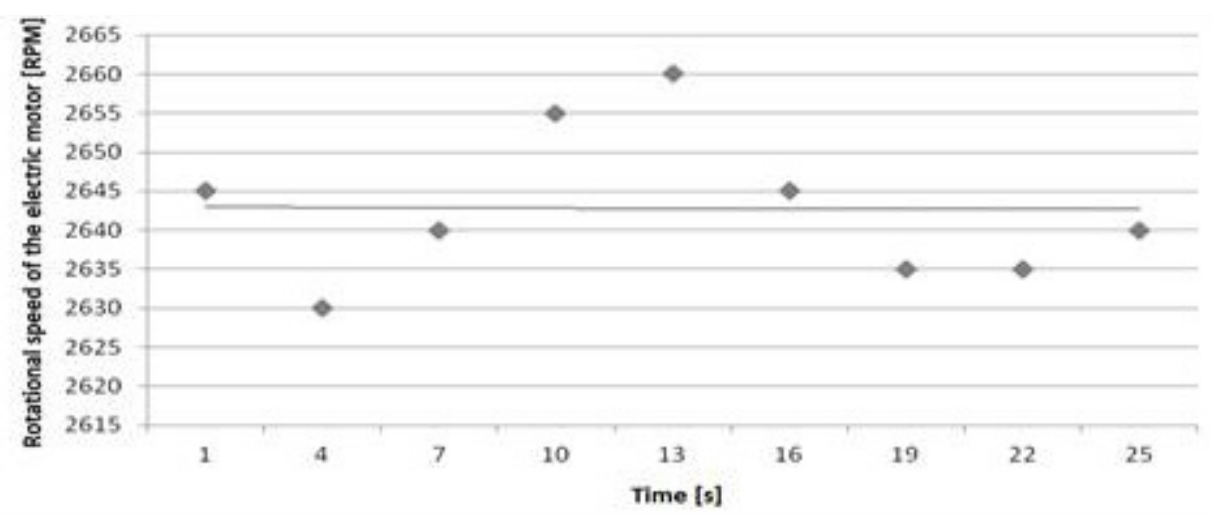

Fig. 4. The rotational speed of the electric motor while driving on straight section of road at $40 \mathrm{~km} / \mathrm{h}$

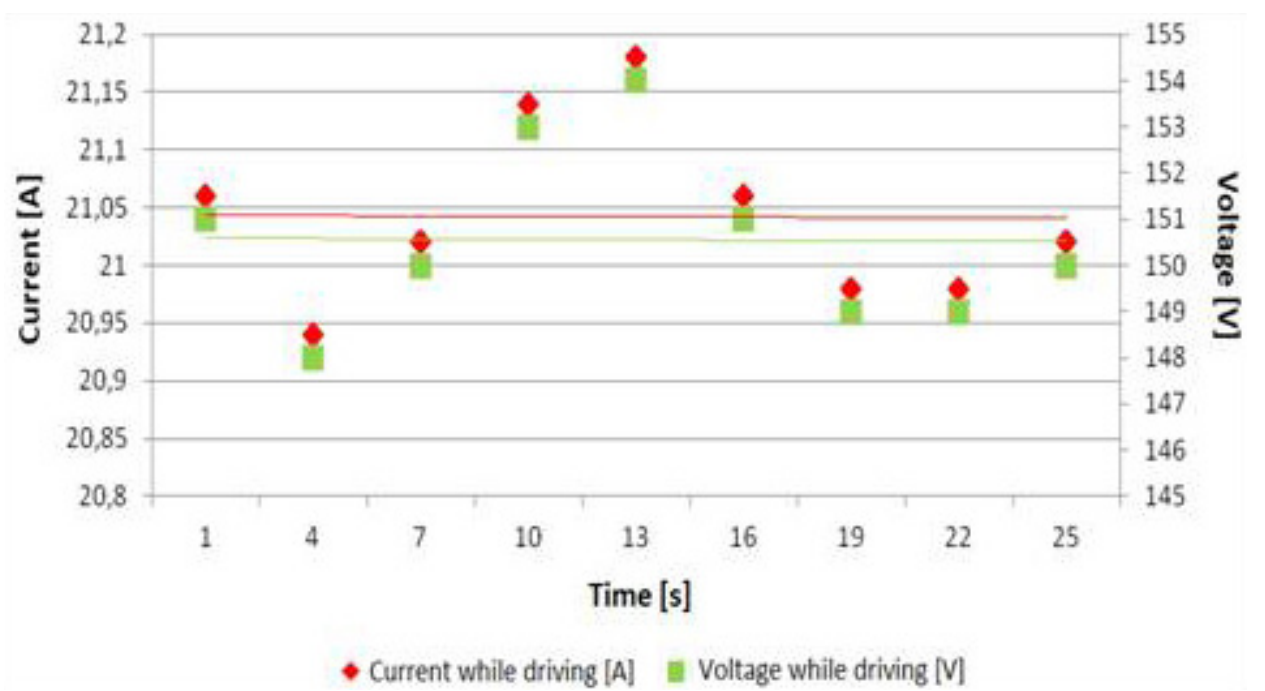

Fig. 5. Current and voltage while driving on the straight section of road at $40 \mathrm{~km} / \mathrm{h}$ 


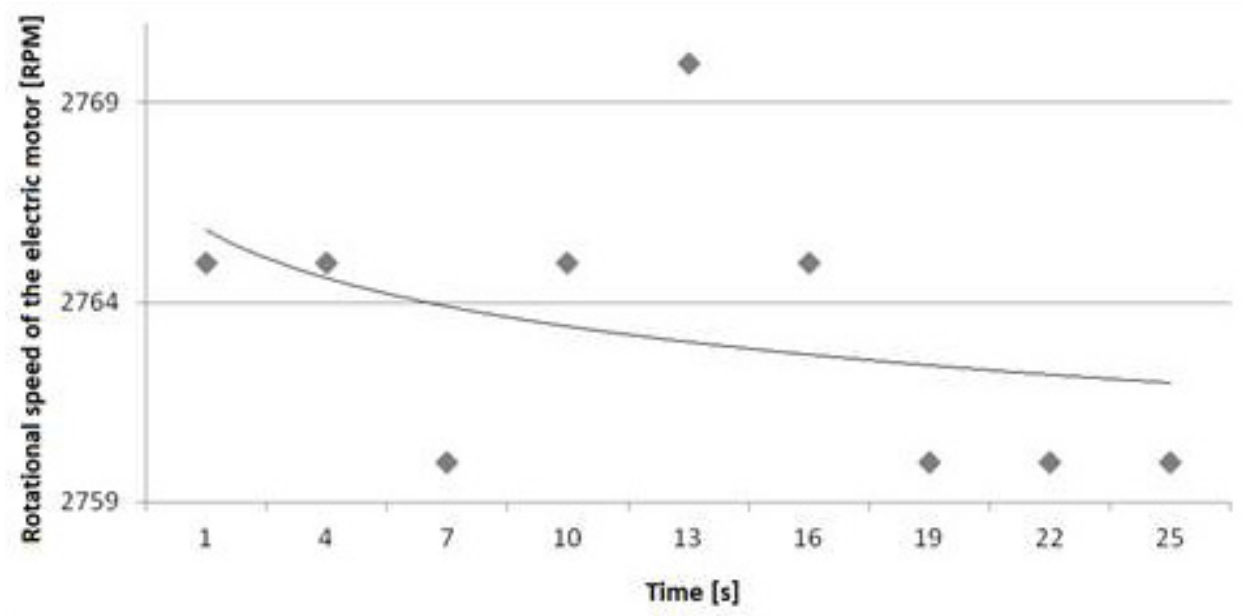

Fig. 6. The rotational speed of the electric motor while driving uphill at a speed of $40 \mathrm{~km} / \mathrm{h}$

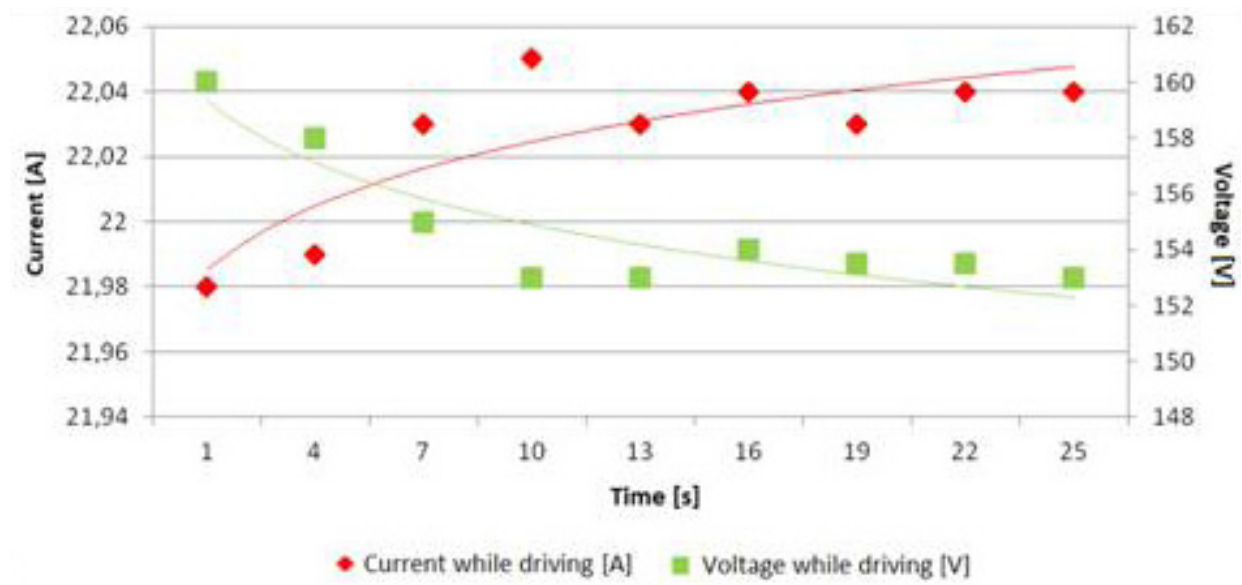

Fig. 7. Current and voltage when driving uphill at a speed of $40 \mathrm{~km} / \mathrm{h}$

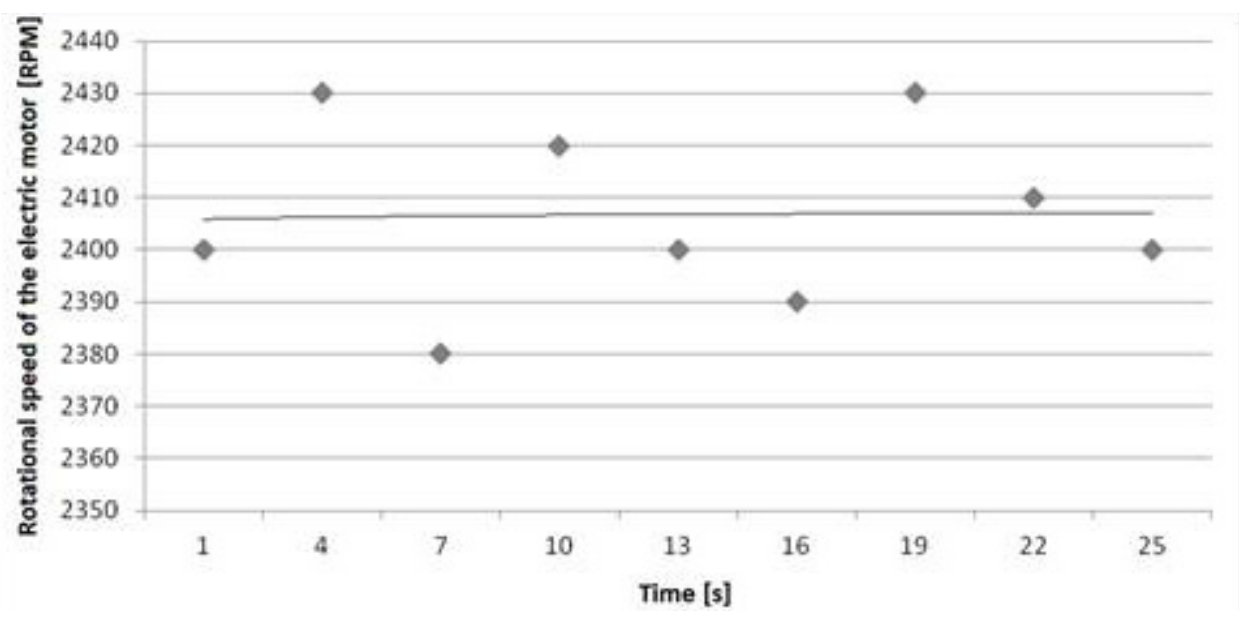

Fig. 8. The rotational speed of the electric motor when driving downhill at speed of $40 \mathrm{~km} / \mathrm{h}$ 


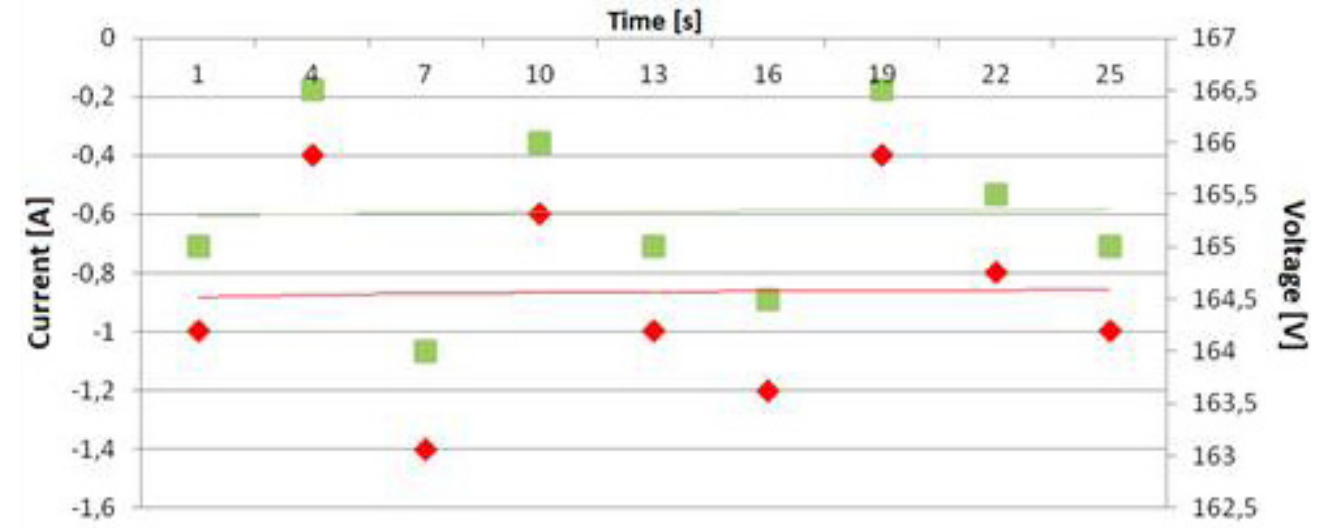

- Current while driving [A] $=$ Voltage while driving [V]

Fig. 9. The current and voltage when driving downhill at speed of $40 \mathrm{~km} / \mathrm{h}$

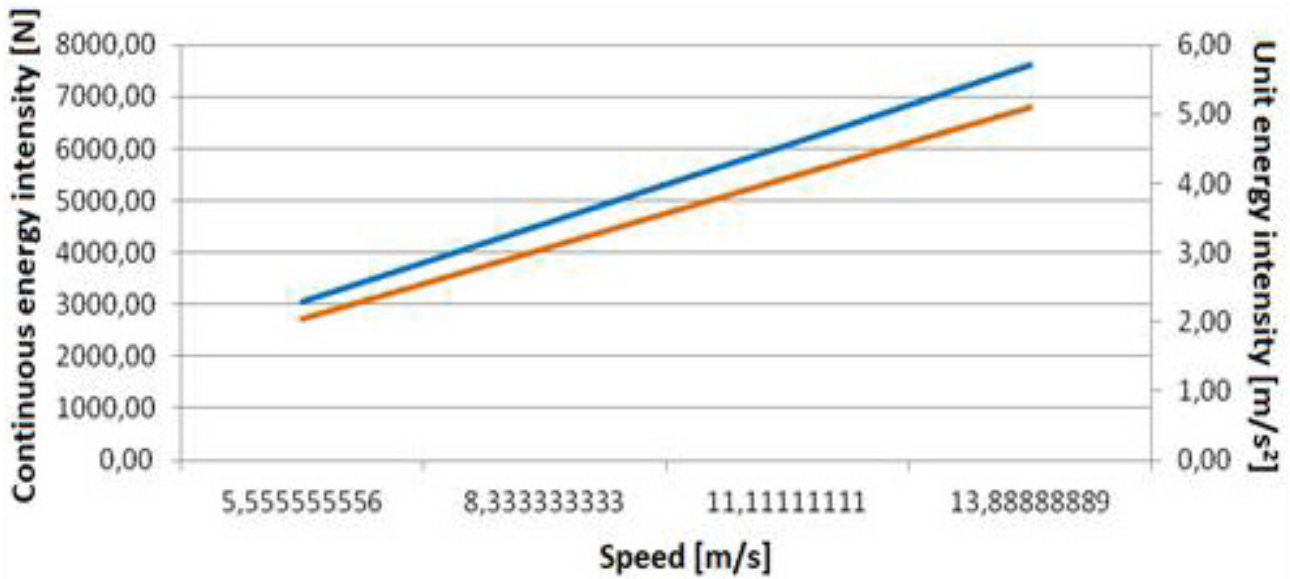

- Continuous energy intensity $[\mathrm{N}]$ Unit energy intensity $\left[\mathrm{m} / \mathrm{s}^{2}\right]$

Fig. 10. Graph of continuous and unit energy intensity while driving the vehicle on straight road by hybrid vehicle

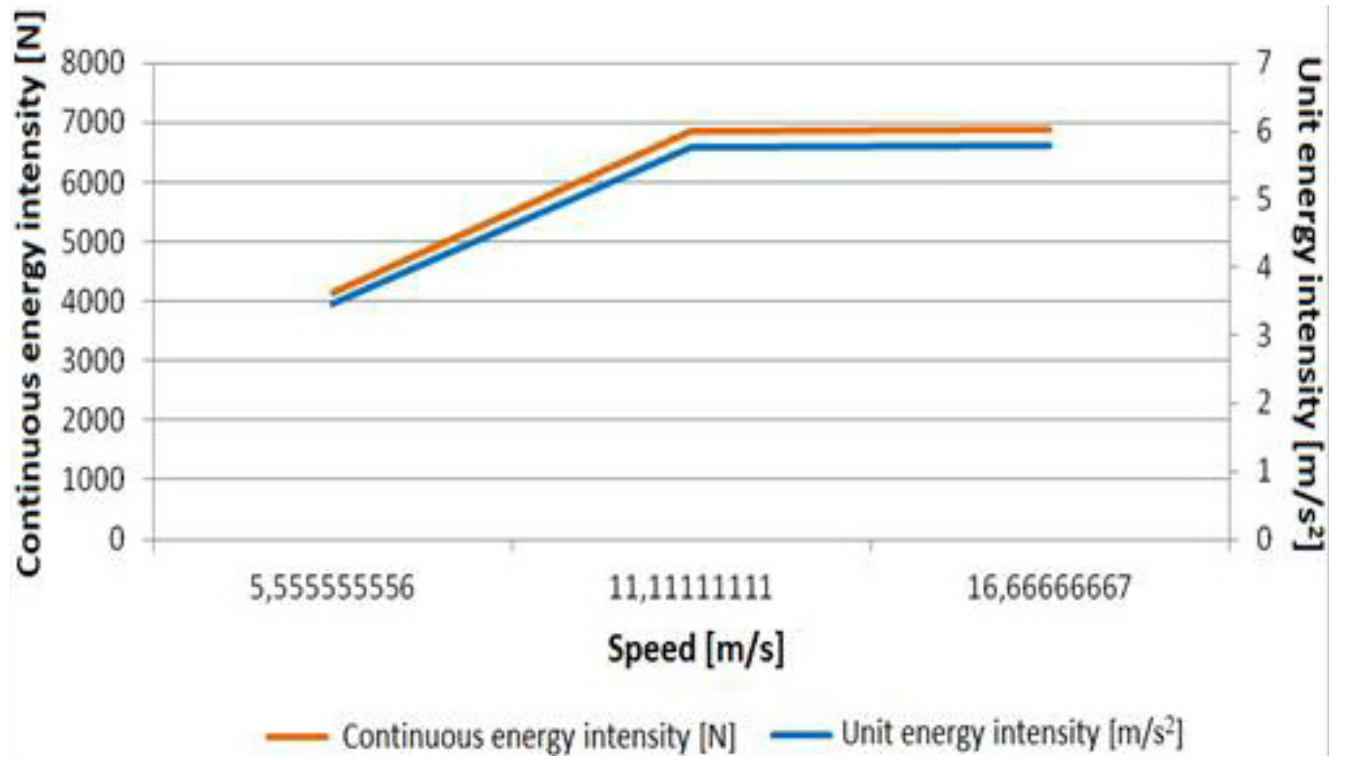

Fig. 11. Graph of continuous and unit energy intensity while driving uphill by the hybrid vehicle 


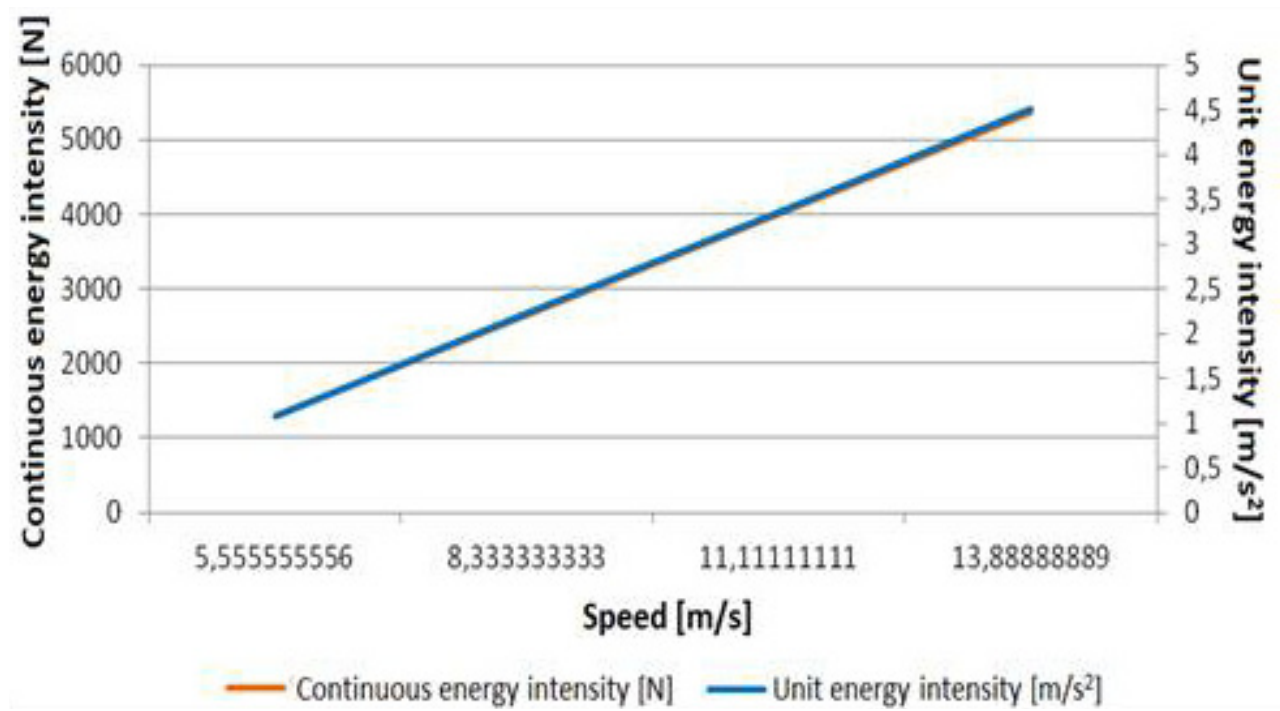

Fig. 12. Graph of continuous and unit energy intensity while driving downhill by the hybrid vehicle

\section{EXPERIMENTAL RESEARCH}

The object of the test was a hybrid vehicle with an internal combustion engine with a capacity of $1497 \mathrm{~cm} 3$ and a power of $55 \mathrm{~kW}(75 \mathrm{HP})$ and a torque of $111 \mathrm{Nm}$ and an electric motor with a maximum power of $45 \mathrm{~kW}(62 \mathrm{~km})$ and a torque of $169 \mathrm{Nm}$. Power is transmitted to the front wheels through a continuously variable transmission ECVT. Figure 3 presents a block diagram of the hybrid drive system used in the test vehicle $[1,5-8]$

During the research, the vehicle was attached to a mass of $150 \mathrm{~kg}$. Registrations of the results were conducted by driving EV (Electric Vehicle). During the research, the following values were recorded: engine speed, voltage to the motor and current. The measurements were carried out for 4 speeds and 2 driving profiles: driving up and driving downhill:

- while driving on straight section of road at a speed of $20 \mathrm{~km} / \mathrm{h}, 30 \mathrm{~km} / \mathrm{h}, 40 \mathrm{~km} / \mathrm{h}, 50 \mathrm{~km} / \mathrm{h}$ (Fig. 4 and 5);

- when driving uphill at a speed of $20 \mathrm{~km} / \mathrm{h}, 40$ $\mathrm{km} / \mathrm{h}, 60 \mathrm{~km} / \mathrm{h}$ (Fig. 6 and 7);

- when driving downhill at a speed of $20 \mathrm{~km} / \mathrm{h}$, $30 \mathrm{~km} / \mathrm{h}, 40 \mathrm{~km} / \mathrm{h}, 50 \mathrm{~km} / \mathrm{h}$ (Fig. 8 and 9).

On the basis on the research and calculations, we can observe changes in energy consumption of the traction unit and movement. Energy intensity of the movement of the hybrid vehicle: while driving on a straight road, when driving uphill and downhill was presented on the drawings (Figures $10-12$ ).

\section{CONCLUSION}

1. On the basis of the research, it can be stated that the greatest value of energy intensity occurs while driving uphill, and the smallest when driving downhill. The amount of energy required while driving uphill at a speed of $20 \mathrm{~km} / \mathrm{h}$ allows you to drive on an equal distance at a speed of $30 \mathrm{~km} / \mathrm{h}$, and when driving downhill at a speed of $40 \mathrm{~km} / \mathrm{h}$. While driving uphill, the vehicle takes twice the current value than when driving downhill.

2. Fuel savings in hybrid vehicles oscillate between approx. 30\% in comparison with vehicles with internal combustion engines.

3. When analyzing driving by the vehicle with the hybrid system, fuel consumption of combustion engine with $100 \mathrm{hp}$ is reduced by $29 \%$.

\section{REFERENCES}

1. Adamiec M. and Dziubiński M. Alkaline fuel cell - aspect of efficiency. Przegląd Elektrotechniczny, 4, 2009.

2. Bartłomiejczyk M. and Połom M. Spatial aspects of the efficiency of regenerative braking in communication trolleybus. Logistyka, 6, 2013

3. Chłopek Z. Examination of the energy consumption of an electric car. Archiwum Motoryzacji, 3, 2012

4. Chłopek Z. Rating the energy consumption of public buses. Journal of KONES, 13(1), 2006 
5. Dziubiński M. Ecological aspect of electronic ignition and electronic injection system. Environment engineering V. CRC Press Taylor and Francis Group, 2016, 299-304.

6. Dziubiński M. Testing of exhaust emissions of vehicles combustion engines. Environment engineering V. CRC Press Taylor and Francis Group, 2016, 305-310.

7. Dziubiński M., Drozd A., Adamiec M. and Siemionek E. Electromagnetic interference in electrical systems of motor vehicles. Materials Science and Engineering. IOP Conference Series, 148, 2016.

8. Dziubiński M., Drozd A., Adamiec M. and Siemionek E. Energy balance in motor vehicles. Materials Science and Engineering. IOP Conference Series, 148, 2016.

9. Hamacek S., Bartłomiejczyk M., Hrbá R., Misák S. and Styskala. V. Energy recovery effectiveness in trolleybus transport. Electric Power Systems Research, 7, 2014.
10. Merkisz J., Molik P., Nowak M. and Ziółkowski A. Driving cycles in public transport vehicles on the example of the Poznań agglomeration. Logistyka, 3, 2012

11. Rudnicki T. Vehicles with electric motor. Zeszyty Problemowe-Maszyny Elektryczne, 80, 245-250.

12. Siemionek E. Analysis of the energy intensity of the movement of trolley buses. Advances in Science and Technology Research Journal, 7(18), 2013, 81-84

13. Siemionek E. and Dziubiński M. Testing energy consumption in the trolleybus and the bus on a chosen public transport line in Lublin. Advances in Science and Technology Research Journal, 9(26), 2015, 152-160.

14. Siłka W. The theory of car movement. WNT, Warsaw 2002.

15. Sun F., Bin L. and Wang Z. Analysis of Energy Consumption Characteristics of Dual-source Trolleybus, Transportation Electrification Asia-Pacific. 2014 IEEE Conference and Expo Beijing. 